\title{
Could Low Hdl-Cholesterol Levels Be an Unvalued Predictor of Cancer Risk?: A Retrospective Case Study
}

\author{
Juan Antonio Vílchez ${ }^{1,2^{*}}$, Natalia Sancho-Rodríguez ${ }^{3 *}$, Ana Martínez-Ruiz ${ }^{1}$, \\ Enrique Martínez-Sánchez ${ }^{1}$, Francisco Ruiz-Espejo' ${ }^{1}$, Isabel Tovar-Zapata ${ }^{1}$, \\ Jose Antonio Noguera-Velasco ${ }^{1}$ \\ ${ }^{1}$ Clinical Analysis Department, Virgen de la Arrixaca Clinic University Hospital, Murcia, Spain \\ ${ }^{2}$ Cardiology Department, Virgen de la Arrixaca Clinic University Hospital, Murcia, Spain \\ ${ }^{3}$ Laboratorios Unilabs S. L., Murcia, Spain \\ Email: "juananv81@hotmail.com
}

Received 20 February 2015; accepted 28 December 2015; published 31 December 2015

Copyright $@ 2015$ by authors and Scientific Research Publishing Inc.

This work is licensed under the Creative Commons Attribution International License (CC BY). http://creativecommons.org/licenses/by/4.0/

\section{cc) (i) Open Access}

\section{Abstract}

Background: The relationship between serum lipid profile levels and cancer risk remained uncertain. Recently, it had been reported a significant inverse association between high-density lipoprotein cholesterol (HDL) and the risk of incident cancer that was independent of low-density lipoprotein cholesterol (LDL), age or sex. Objective: The aim of our study was to evaluate the behavior of HDL in cancer patients and in healthy population. Methods: We created a retrospectively search strategy in the laboratory information system (LIS). We filtered and searched those patients with CEA within $5-20 \mathrm{ng} / \mathrm{ml}$ and any value of HDL and corroborated the presence of cancer (Group 1 (G1)) or not (Group 2 (G2)). Moreover, we searched a control group (patients in outpatient oncology clinic) to observe the values of HDL. Comparisons and statistical logistic regression models were applied to link the levels of this biomarkers and cancer risk. Results: We examined 852 valid patients, median age $62(50$ - 73) years. Within the search strategy group, G2 showed highest levels of HDL (54 (43 - 67) $\mathrm{mg} / \mathrm{dl})$ and lowest CEA levels $(6.7(5.7-8.4) \mathrm{ng} / \mathrm{ml})$ comparing with G1: HDL (47 $(37-60) \mathrm{mg} / \mathrm{dl})$ and the CEA $(7.9(6.2-10.9) \mathrm{ng} / \mathrm{ml}) ; p<0.001$. The values in control group were: the lowest HDL levels $(41(29-54) \mathrm{mg} / \mathrm{dl})$ and CEA $(25.2(6.1$ - 124.5) ng/ml); $p<0.001$, between oncologic patients and the search strategy group. On logistic regression multivariate analysis, we obtained: $r^{2}$ : 0.092; $p<0.001$; HDL [OR: $\left.0.983(0.974-0.993),(p=0.001)\right]$ and CEA [OR: $1.115(1.060-1.174),(p<0.001)]$ and they were confirmed as independent predictors of cancer. Conclusion: Our findings confirmed the inverse association of HDL levels between healthy

\footnotetext{
*Both authors contributed equally.

\#Corresponding author.
} 
populations and were diagnosed with cancer. Moreover, in a random population, patients with cancer presented lower HDL values compared to those without cancer. Therefore, it could demonstrate the possible positive predictive value of low HDL related to cancer risk.

\section{Keywords}

\section{High-Density Lipoprotein Cholesterol (HDL), Cancer Risk, Lipid Profile, Carcinoembryonic Antigen (CEA)}

\section{Introduction}

Relationship between serum lipid profile levels and cancer remains uncertain. Several epidemiological studies have shown a correlation between increased hypercholesterolemia at the study baseline, and the occurrence of certain cancers, particularly breast cancer and other gynecologic cancers [1]-[3]. Indeed, low serum total cholesterol (TC) has been associated with increased mortality and cancer [4]-[6] and hence, inversely associated with cancer risk. Furthermore, high levels of triglycerides (TG) have been associated to the incidence of different cancers [7] [8]. But, low concentrations of high-density lipoprotein cholesterol (HDL) have been studied the most, linking low HDL levels with higher cancer risk, in different types of cancers [1] [2] [6] [9]-[14]. Furthermore, recent meta-analysis by Jafri H. et al. [15] has reported a significant inverse association between HDL and the risk of incident cancer that is independent of low-density lipoprotein cholesterol (LDL), age or sex. Also it appears a relation between serum lipid metabolism and risk of obesity-related cancers [16] and nowadays, obesity is a problem that grows up in the western society. This topic is becoming an interesting discussed aspect in recent literature [16] [17].

Taking into account that low HDL seems to be the lipoprotein levels with most interesting results related to prediagnostic cancer [1] [2] [6] [12] [15] [16] [18]-[22], we decide to choose a retrospective study. We created a search strategy in the laboratory data base, filtering the population groups using the carcinoembryonic antigen (CEA), as a general non-specific tumor marker involved in many types of cancer. CEA is the preferred tumor marker related to predict the prognosis in patients with colorectal cancer and also can be elevated in lung [23] [24], breast [25], cervical [26], liver, thyroid, stomach cancer [27], etc. Knowing this, we filtered the study population with the purpose to select a possible group of population that could present cancer or not, and could avoid the extended laboratory database. Therefore, the principal aim of this retrospective observational study is to evaluate the behavior of HDL levels in a possible "healthy" population, in a population with high probability of developing early cancer and moreover in oncologic patients previously diagnosed.

\section{Patients and Methods}

\subsection{Patients Search Strategy}

We examined retrospectively 1025 patients evaluating the relationship between HDL and CEA, as the main non-specifically tumor marker implicated in several cancers. HDL over $60 \mathrm{mg} / \mathrm{dl}$ is considered an optimum level and values $<40 \mathrm{mg} / \mathrm{dL}$ is associated with atherosclerotic risks [28]. The normal range of CEA serum levels varies between laboratories, but levels higher $5 \mathrm{ng} / \mathrm{ml}$ must to be observed. The range between 5 - $20 \mathrm{ng} / \mathrm{ml}$ are not normal, but can also be elevated by some non-cancerous diseases such as liver cirrhosis, chronic renal failure, chronic obstructive pulmonary disease, the presence of polyps, and otherwise "healthy" smokers (around 5\% 7\%). But CEA concentrations above $>25 \mathrm{ng} / \mathrm{ml}$, approximates to a 95\% of probability to present a cancer diagnostic [24] [25] [29]. Knowing these criteria we created a search strategy in the laboratory information system (LIS) (Omega 3000, Roche Diagnostics, Mannheim, Germany) to observe mainly the HDL behavior. This strategy was applied for three years. Firstly, we filtered patients on LIS, searching those patients with CEA between 5 - $20 \mathrm{ng} / \mathrm{ml}$ and any value of HDL. This strategy quest, was created to observe slightly but significant high levels of CEA, on patients who were corroborated the presence of any type of cancer (Group 1 (G1)) or not (Group 2 (G2)), by consulting medical records. Moreover we searched for patients from oncology department, and they were selected as the control group: patients previously diagnosed with cancer. This patients presented 
higher levels of CEA and we observed any value of HDL.

We studied the levels of lipid profile: TC, calculated low-density lipoprotein cholesterol (LDL), HDL in those groups. We collected data of alkaline phosphatase (ALP), creatinin, CEA and moreover, we registered the different main types of cancer on CEA is predominantly elevated (colorectal, breast, lung cancer (non-small cell lung cancer (NSCLC) and others).

For this retrospective observational study, all patients were informed and consented to participate on it. The Research Ethics Committee approved the study in accordance with the Declaration of Helsinki, as amended in Edinburgh in 2000.

\subsection{Methods}

The analytical results searched in the laboratory information management system (LIS) offered us a selected number of patients to collect the required data. All the analytical tests were performed in automated platforms as Hitachi or Cobas 6000 (Roche Diagnostics, Mannheim, Germany). HDL levels were assessed by a direct determination using polyethylene-glycol modified enzymes and dextran-sulfate. CEA levels were assessed by an electrochemiluminescence method. The electronic clinical history data of the patients was collected using SELENE platform (Siemens).

\subsection{Statistical Analysis}

Each categorical variable was expressed as frequency (percentage) of patients. Continuous variables were tested for normal distribution by the Kolmogorov-Smirnov test, only TC follow behave a normal distribution. The normal distributed continuous variables are shown as mean $\pm \mathrm{SD}$, and those non-parametrically distributed are shown as median (interquartile range). Differences between groups were assessed by the unpaired t-test for independent samples, the Mann-Whitney U test (as appropriate) for continuous variables. Correlation was performed between two continuous variables by Spearman test. A two-side probability value of $p<0.05$ was considered statistically significant. Multivariate analysis by logistic binary regression was used to identify the factors associated to the presence of cancer. Variables with $p<0.15$ in the univariate analysis were included into the multivariate regression model. A linear multivariate regression model was also evaluated. Performance of these tests was evaluated using receiver-operating characteristics (ROC) curves and the best cutoff point for HDL and CEA were applied. HDL and CEA levels were dichotomized as "low" or "high" according to whether the circulating levels were under or over the calculated threshold (cut-off). This dichotomy for HDL and CEA were assessed into the logistic regression model to explore the overall predictive value of theme upon cancer. Statistical analyses were carried out with SPSS version 15.0 software (Chicago, Illinois, USA).

\section{Results}

We examined retrospectively 1025 patients, finally 852 valid (48\% men and 52\% women), mean age 62 (50 73). All the descriptive results are shown in Table 1. Within the search strategy group, G2 (No cancer) showed highest levels of HDL (54 (43 - 67) $\mathrm{mg} / \mathrm{dl})$ and lowest CEA levels (6.7 (5.7 - 8.4) ng/ml) comparing with G1: HDL (47 (37 - 60) mg/dl) and the CEA (7.9 (6.2 - 10.9) ng/ml), both of them $p<0.001$ (Figure 1). Moreover, the values in the control group (patients from oncologic department) observed were: the lowest HDL levels (41 $(29$ - 54) $\mathrm{mg} / \mathrm{dl})$ and CEA $(25.2(6.1-124.5) \mathrm{ng} / \mathrm{ml}) ; p<0.001$ between oncology patients and the search strategy group. HDL and CEA showed no signification correlation between them $(r=-0.22 ; p=0.876)$. The percentage of different types of cancer in the oncology control group was: Colorectal: 28.3\%, Breast: 14.3\%, Lung Cancer (NSCLC): $12.1 \%$, tumors that present a marked elevated CEA. The remaining was a $45.3 \%$ of various cancers, data very closed to the one observed in G1 group (Table 1). In addition, statistically significant differences between G1 and G2 were observed for creatinine (0.83 (0.70 - 1.05) vs. $0.9(0.7-1.12),(p=0.017))$ and alkaline phosphatase (89 (72 - 121) vs. 82 (66 - 109), $(p=0.003)$ ). The rest of descriptive variables (lipid profile remaining) did not showed statistically significant differences between groups.

On univariate analysis (Table 2$)$, creatinine $(p=0.014)$, HDL $(p<0.001)$ and CEA $(p<0.001)$ were independent predictors of cancer development. Also confirmed on logistic regression multivariate analysis, $r^{2}: 0.092$; $p<0.001$ : creatinine (OR (95\% CI) 0.841 (0.736 - 0.960), $(p=0.010)$ ), HDL (OR: 0.983 (0.974 - 0.993), $(p=$ 
Table 1. Descriptive clinical characteristics of patients.

\begin{tabular}{|c|c|c|c|c|}
\hline \multirow[b]{2}{*}{ Characteristics } & \multicolumn{3}{|c|}{ Search Strategy Group } & \multirow{2}{*}{$\begin{array}{c}\text { Control Group } \\
\text { (Oncology Patients) } \\
(\mathrm{N}=200)\end{array}$} \\
\hline & $\begin{array}{c}\text { G1 (Cancer) } \\
(\mathrm{N}=230)\end{array}$ & $\begin{array}{l}\text { G2 (No Cancer) } \\
(\mathrm{N}=422)\end{array}$ & $p$ Value & \\
\hline Age (years) & $62.7 \pm 12.4$ & $63.7 \pm 14.6$ & 0.379 & $57.3 \pm 72.5$ \\
\hline $\begin{array}{l}\text { Sex (\%) Male } \\
\text { Female }\end{array}$ & $\begin{array}{l}46 \% \\
54 \%\end{array}$ & $\begin{array}{l}45.7 \% \\
54.3 \%\end{array}$ & 0.939 & $\begin{array}{l}55 \% \\
45 \%\end{array}$ \\
\hline $\begin{array}{c}\text { Cancer (\%) } \\
\text { Colorectal } \\
\text { Breast } \\
\text { Lung (NSCLC) } \\
\text { Others }\end{array}$ & $\begin{array}{c}26 \% \\
22.7 \% \\
18.3 \% \\
33 \%\end{array}$ & $\begin{array}{l}- \\
- \\
- \\
-\end{array}$ & $\begin{array}{l}- \\
- \\
- \\
-\end{array}$ & $\begin{array}{l}28.3 \% \\
14.3 \% \\
12.1 \% \\
45.3 \%\end{array}$ \\
\hline $\begin{array}{c}\text { Creatinine (mg/dl) } \\
\text { Total cholesterol (mg/dl) } \\
\text { LDL (mg/dl) } \\
\text { HDL (mg/dl) } \\
\text { Alkaline phosphatase (U/L) } \\
\text { CEA (ng/ml) }\end{array}$ & $\begin{array}{c}0.83[0.70-1.05] \\
195.6 \pm 50.8 \\
89[65-109] \\
47[37-60] \\
89[72-121] \\
7.9[6.2-10.9]\end{array}$ & $\begin{array}{c}0.9[0.7-1.12] \\
196.9 \pm 50.1 \\
83[60-111] \\
54[43-67] \\
82[66-109] \\
6.7[5.7-8.4]\end{array}$ & $\begin{array}{c}\mathbf{0 . 0 1 7} \\
0.750 \\
0.515 \\
\mathbf{0 . 0 0 1} \\
\mathbf{0 . 0 0 3} \\
<\mathbf{0 . 0 0 1}\end{array}$ & $\begin{array}{c}0.7[0.5-0.9] \\
183.9 \pm 78.6 \\
110.5[74.4-150.2] \\
41[29-54] \\
82[63-115] \\
25.2[6.1-124.5]\end{array}$ \\
\hline
\end{tabular}

Table 2. Binary regression analysis for the endpoint of Cancer (yes or not).

\begin{tabular}{|c|c|c|c|c|}
\hline \multirow{3}{*}{$\begin{array}{l}\text { Model of Binary } \\
\text { Regression }\end{array}$} & \multicolumn{4}{|c|}{ Cancer } \\
\hline & \multicolumn{2}{|c|}{ Univariate Analysis } & \multicolumn{2}{|c|}{ Multivariate Analysis } \\
\hline & OR (95\% CI) & $p$ Value & OR (95\% CI) & $p$ Value \\
\hline Age & $0.995(0.983-1.007)$ & 0.40 & & \\
\hline Sex & $0.975(0.719-1.323)$ & 0.87 & & \\
\hline Creatinine (mg/dl) & $0.848(0.744-0.967)$ & 0.014 & $0.841(0.736-0.960)$ & 0.010 \\
\hline TC (mg/dl) & $0.999(0.996-1.003)$ & 0.750 & & \\
\hline LDL (mg/dl) & $1.001(0.997-1.005)$ & 0.691 & & \\
\hline HDL (mg/dl) & $0.984(0.975$ - 1.0059) & $<0.001$ & $0.983(0.974-0.993)$ & 0.001 \\
\hline $\operatorname{ALP}(\mathbf{U} / \mathbf{L})$ & $1.002(1-1.005)$ & 0.060 & & \\
\hline CEA (ng/ml) & $1.128(1.074-1.185)$ & $<0.001$ & $1.115(1.060$ - 1.174) & $<0.001$ \\
\hline
\end{tabular}

0.001)) and CEA (OR: $1.115(1.060-1.174),(p<0.001))$. This significant factors were used to confirmed in a multivariate model: $r$ : 0.231, $r^{2}: 0.053 ; p<0.001$, (CEA: 0.026 (0.016 - 0.036); $p<0.001$ and HDL: -0.003 $(-0.005 /-0.001) ; p=0.002)$. But, the other lipid parameters did not present significance in our multivariable analysis. This model was also confirmed with a model of linear regression, assuming as dependent variable, cancer yes or not: HDL offered a negative consentient value OR (95\% CI): $-0.003(-0.005 /-0.001) ; p<0.001$ and CEA: 0.027 (0.017 - 0.038); $p<0.001$.

On constructing the ROC curve for HDL and CEA levels obtained (AUC: $0.580(0.535-0.626) ;(p=0.001)$ ) and (AUC: 0.607 (0.560 - 0.654); $(p<0.001)$ ) respectively. The best HDL and CEA cut-off levels for the development of cancer were $37.5 \mathrm{mg} / \mathrm{ml}$ and $6.4 \mathrm{ng} / \mathrm{ml}$. This cut-off concentration had a sensitivity value of $82.7 \%$ and a specificity value of $23.9 \%$ for HDL and a sensitivity value of $65 \%$ and a specificity value of $43.6 \%$ for CEA. The combination of both markers offered an increase in the AUC to 0.638 (0.592 - 0.683) (Table 3).

Univariate analysis model with the cut-off values chosen for HDL $\leq 37.5 \mathrm{mg} / \mathrm{dl},(p=0.043)$ and CEA $\geq 6.4$ ng/ml, ( $p=0.033$ ) appeared like they were predictors of cancer development (Table 4). Also, on multivariate analysis both cut-off, HDL $\leq 37.5 \mathrm{mg} / \mathrm{dl}$ (OR: 1.429 (1.023 - 1.995); $(p=0.018)$ ) and CEA $\geq 6.4$ ng/dl OR: 1.453 (0.977 - 2.162); $(p=0.045))$ were independent predictors of cancer $\left(r^{2}: 0.017 ; p=0.018\right)$. 


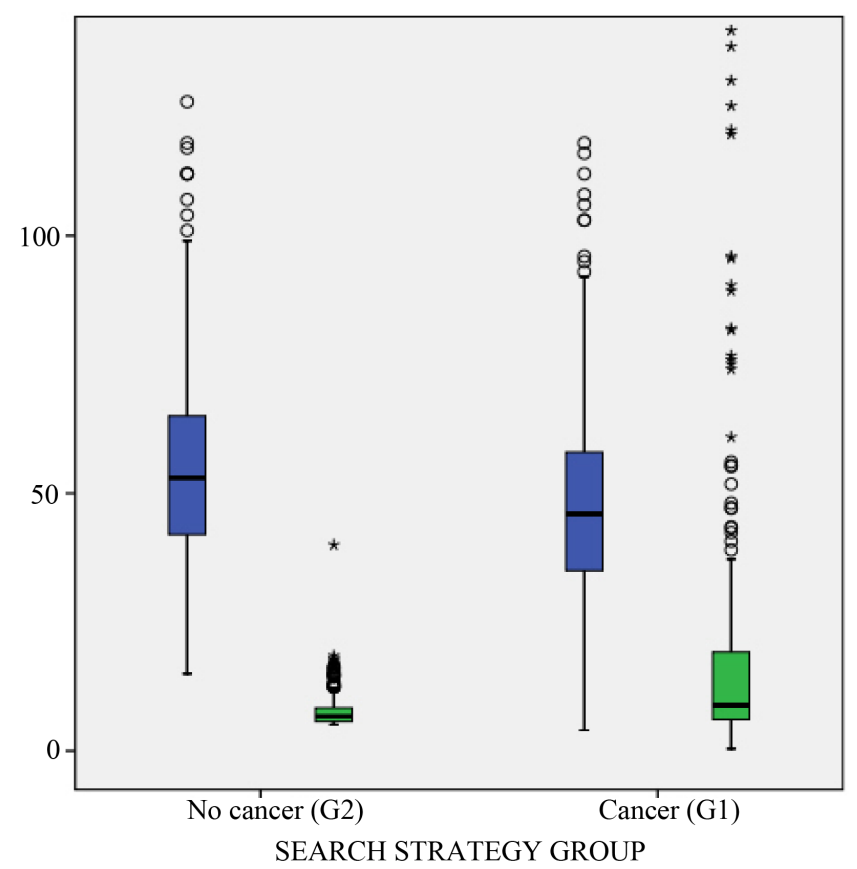

Figure 1. Comparison of the levels of HDL and CEA among the patients searched and the oncology control group ( $p<$ 0.001).

Table 3. ROC curve analyses with the best cutoff point chosen for the event of presence of cancer.

\begin{tabular}{cccc}
\hline Event: Cancer & HDL $(\mathbf{m g} / \mathbf{d l})$ & CEA (ng/d) & HDL + CEA \\
\hline $\boldsymbol{p}$ Value & 0.001 & $<0.001$ & $<0.001$ \\
Cutoff point & 37.5 & 6.4 & - \\
AUC (CI 95\%) & $0.580(0.535-0.626)$ & $0.607(0.560-0.654)$ & $0.638(0.592-0.683)$ \\
Sensitivity & $82.7 \%$ & $65 \%$ & - \\
Specificity & $23.9 \%$ & $43.6 \%$ & - \\
\hline
\end{tabular}

Table 4. Binary regression analysis for the endpoint of cancer (yes or not), with a cut-off chosen by ROC curves method.

\begin{tabular}{ccccc}
\hline $\begin{array}{c}\text { Model of } \\
\text { Binary } \\
\text { Regression }\end{array}$ & \multicolumn{3}{c}{ Cancer } \\
\cline { 2 - 5 } & OR (IC 95\%) & $\boldsymbol{p}$ Value & OR (IC 95\%) & $p$ Value \\
HDL $\leq \mathbf{3 7 . 5}$ & $1.503(1.013-2.229)$ & $\mathbf{0 . 0 4 3}$ & $1.429(1.023-1.995)$ & $\mathbf{0 . 0 1 8}$ \\
CEA $\geq \mathbf{6 . 4}$ & $1.401(1.031-2.007)$ & $\mathbf{0 . 0 3 3}$ & $1.453(0.977-2.162)$ & $\mathbf{0 . 0 4 5}$ \\
\hline
\end{tabular}

\section{Discussion}

We presented in this retrospective study, interesting data about the behavior of HDL and the presence of cancer. Filtering population to select different groups, we observed in those patients from oncology (our control group) how they showed lowest values of HDL 41 (29-54) mg/dl, in which the medium rubbed the normal HDL population values ( $40-60 \mathrm{mg} / \mathrm{dl}$ ) and the 25th percentile value of $29 \mathrm{mg} / \mathrm{dl}$, was very far away of normal values, with a really low HDL level (Table 1). Furthermore, this behavior is corroborated in the main objective of our study, which was to have a random population, selecting by CEA values, within $5-20 \mathrm{ng} / \mathrm{ml}$, which means to obtain healthy patients (G2) and confirmed cancer patients (G1). So, the HDL behavior observed in the group 
who also suffered some cancer was a low HDL values 47 (37-60) mg/dl, compared to those without cancer, confirming our theory to find lower values of HDL related to cancer patients. Interestingly, a strong and significant inverse relationship has been reported recently between baseline HDL cholesterol and the incidence of cancer [15], in some meta-analysis. The median baseline HDL for all included in the Jafri et al. meta-analysis was 44.4 (39.0 - $47.4 \mathrm{mg} / \mathrm{dl}$ ), a similar median obtained in our study and also similar to the one presented by, Ahn J. et al. [6] that also previously evaluated the prediagnostic HDL related to cancer risk. They showed in the ATBC cohort how high serum TC were associated with decreased overall cancer incidence in the multivariate model and also high serum HDL levels (median of $46.3 \mathrm{mg} / \mathrm{dL}$ ) was modestly, but significantly, associated with decreased cancer incidence. They excluded all cases diagnosed during the first 12 years of follow-up, arguing against an effect of preclinical disease on serum concentrations. These findings are consistent with the Framingham Offspring Study [30], but it is needed future consistent designs with the same exclusion of firstly years of follow-up, as we discussed recently [17].

This theory is further supported in our study performing a linear regression model, in which HDL provides a negative correlation of HDL related to increased risk of cancer, contrary to the positive OR of CEA, as was supposed. Also in the binary logistic regression are provided significant OR below 1 for HDL and above 1 to CEA (Table 2). Thus, we saw that CEA was also a good filter in our population (they also did not confirm to depend on each other, in the Spearman correlation). Moreover, we see in our group of tumors that the most prevalent were those that have higher elevations of CEA traditionally related (colon, NSCLC, metastatic breast cancer...) [24] [25] [29].

These data was also corroborated in other meta-analysis by Melvin J.C. et al. [16], linking between serum markers of lipid metabolism and risk of obesity-related cancers, with different pooled models that link not only low HDL levels (<1.03 mmol/L), also low Apoliprotein-A (apoA) or high TC and TG, using clinical cut-points. But, we only could show similar results for HDL levels. Therefore, with the same approach, proposing cut-off points with ROC curves, used in the meta-analysis by Melvin J.C. et al., we tried to confirm a possible cut-off value of HDL, CEA related to cancer risk, as we could observe in the improvement AUC value, using both together (Table 3). In this case, we aimed to show the relevance for clinicians to take into account those repeated low concentrations of HDL in patients without associated pathology. Especially, focusing in the fact that HDL is a common parameter requested in basic analytics, however no other biomarkers, as tumour markers, are requested in routine analytic, and those are the ones that use to give some suspicion of malignancy in patients. But it is important to note that, we don't intend to propose such use of this cutoff values in our retrospective study, it has to be confirmed in more prospective studies designed for this topic. Although, it had been previously corroborated in several studies, as we mentioned previously, numerous prospective studies have evaluated HDL levels in relation to the incidence of cancer, upon significant cohorts. Several of those studies related low HDL levels to major risk of prostate cancer [5], gynecologic cancers [3], lung cancer [20], etc. But the main cancer type studied in this topic has been breast cancer, with different results associated to menopausal state, in large cohorts [2] [12] [31] [32].

One of the possible reasons in the increasing incidence of cancers, mainly gynecologic cancers, in affluent societies is the obesity epidemic [16]. The precise aetiology linking obesity and cancer risk is related with an evidenced role of lipid metabolism in tumour development [33]. So, a complex scenario emerges trying to link lipid profile, obesity, inflammation, and cancer risk [13] [16] [17] [19], topic that has to be studied properly.

Furthermore, it has been shown that phytosterol supplementation protects HDL from lipid peroxidation, involving some changes in the physicochemical properties of HDL, induced by their increased phytosterol content. In this context, and taking into account that human HDL protects LDL from oxidative modification, it is noteworthy that apoA-I, the main HDL protein component, was recently shown to inhibit tumour development in mice [34]. In fact, has also been tested, in a transgenic mouse model of inherited breast cancer [35], the effects of a dietary phytosterol supplement on tumour onset and progression. This study demonstrated a protective effect of phytosterol supplementation with an effect in preventing lipoprotein oxidation in mice, a property that could explain their possible anticancer effects since lipoprotein oxidation/inflammation has been shown to be critical for tumour growth. Moreover, other recent studies in mouse models also demonstrates the possible inhibition of hypoxia-inducible factor- $1 \alpha(\mathrm{HIF}-1 \alpha)$ could be a critical mechanism responsible for the suppression of tumor progression by apoA-I mimetic peptides [36]. A fact that accompanies our theory because of apoA-I is the primary protein constituent of HDL. 


\section{Limitations}

Low HDL cholesterol is associated with the presence of high plasma levels of inflammatory mediators, independent of possible confounders such as smoking, alcohol intake, and physical activity or some drugs taken on medical treatments that could affect some hepatic process related to lipid metabolism [19]. That's why, the value of HDL as a negative acute phase reactant, could also be valuable to determine whether the association between low HDL and cancer was due to an increase of inflammation. But we did not have sufficient data of C-reactive protein, for example, to include it in the model as well as other factors, like smoking, obesity or alcohol intake.

The principal limitation of the present study lies in its purely cross-sectional design. We could perform only association analyses, but long-term follow-up of our patients would likely provide additional information to corroborate the proposed value of HDL for predicting cancer progression to poor clinical states, not only the presence or not as we observed in our regression models. But, this observational study was based on an extended and selected patient cohort that could offer potential interesting data.

\section{Conclusions}

Our findings confirmed the inverse association of HDL levels between healthy populations and were diagnosed with cancer. Moreover, we had a random population, selected by CEA values, in which patients with cancer presented lower HDL values than those without cancer, confirmed in statistic regression models. Therefore, it could demonstrate the possible positive predictive value of low HDL related to cancer risk.

1) What is already known about this topic?

The relationship between serum lipid profile levels and cancer remains uncertain. Several epidemiological studies have shown a correlation between low levels of high-density lipoprotein cholesterol (HDL) and higher cancer risk, in different types of cancers. This fact has been casually observed in some of the major multicenter studies.

2) What does this article add?

We evaluate the behavior of HDL in cancer patients (control group), in healthy population and in a population with high probability of developing early cancer.

We have a retrospective random population, selected by CEA values, in which patients with cancer present lower HDL values than those without cancer.

The performance of a linear and binary regression models shows how HDL provides a negative correlation of HDL related to increased risk of cancer, contrary to the positive OR of CEA, as it is supposed.

\section{Acknowledgements}

JA Vílchez holds a research grant "Río Hortega” by the Instituto de Salud Carlos III. A Martínez-Ruiz holds a research grant from the Spanish Association of Pharmaceutical Analysts (AEFA).

\section{Conflict of Interest}

The authors declare that they have no potential conflict of interests to disclose.

\section{References}

[1] Furberg, A.S., Veierod, M.B., Wilsgaard, T., Bernstein, L. and Thune, I. (2004) Serum High-Density Lipoprotein Cholesterol, Metabolic Profile, and Breast Cancer Risk. Journal of the National Cancer Institute, 96, 1152-1160. http://dx.doi.org/10.1093/jnci/djh216

[2] Kucharska-Newton, A.M., Rosamond, W.D., Mink, P.J., Alberg, A.J., Shahar, E. and Folsom, A.R. (2008) HDL-Cholesterol and Incidence of Breast Cancer in the ARIC Cohort Study. Annals of Epidemiology, 18, 671-677. http://dx.doi.org/10.1016/j.annepidem.2008.06.006

[3] Qadir, M.I. and Malik, S.A. (2008) Plasma Lipid Profile in Gynecologic Cancers. European Journal of Gynaecological Oncology, 29, 158-161.

[4] Wulaningsih, W., Garmo, H., Holmberg, L., Hammar, N., Jungner, I., Walldius, G. and Van, H.M. (2012) Serum Lipids and the Risk of Gastrointestinal Malignancies in the Swedish AMORIS Study. Journal of Cancer Epidemiology, 2012, Article ID: 792034.

[5] Mondul, A.M., Weinstein, S.J., Virtamo, J. and Albanes, D. (2011) Serum Total and HDL Cholesterol and Risk of Pro- 
state Cancer. Cancer Causes \& Control, 22, 1545-1552. http://dx.doi.org/10.1007/s10552-011-9831-7

[6] Ahn, J., Lim, U., Weinstein, S.J., Schatzkin, A., Hayes, R.B., Virtamo, J. and Albanes, D. (2009) Prediagnostic Total and High-Density Lipoprotein Cholesterol and Risk of Cancer. Cancer Epidemiology, Biomarkers \& Prevention, 18, 2814-2821. http://dx.doi.org/10.1158/1055-9965.EPI-08-1248

[7] Seth, D., Garmo, H., Wigertz, A., Holmberg, L., Hammar, N., Jungner, I., Lambe, M., Walldius, G. and Van, H.M. (2012) Lipid Profiles and the Risk of Endometrial Cancer in the Swedish AMORIS Study. International Journal of Molecular Epidemiology and Genetics, 3, 122-133.

[8] Lindemann, K., Vatten, L.J., Ellstrom-Engh, M. and Eskild, A. (2009) Serum Lipids and Endometrial Cancer Risk: Results from the HUNT-II Study. International Journal of Cancer, 124, 2938-2941. http://dx.doi.org/10.1002/ijc.24285

[9] Michalaki, V., Koutroulis, G., Syrigos, K., Piperi, C. and Kalofoutis, A. (2005) Evaluation of Serum Lipids and HighDensity Lipoprotein Subfractions (HDL2, HDL3) in Postmenopausal Patients with Breast Cancer. Molecular and Cellular Biochemistry, 268, 19-24. http://dx.doi.org/10.1007/s11010-005-2993-4

[10] Melvin, J.C., Seth, D., Holmberg, L., Garmo, H., Hammar, N., Jungner, I., Walldius, G., Lambe, M., Wigertz, A. and Van, H.M. (2012) Lipid Profiles and Risk of Breast and Ovarian Cancer in the Swedish AMORIS Study. Cancer Epidemiology, Biomarkers \& Prevention, 21, 1381-1384. http://dx.doi.org/10.1158/1055-9965.EPI-12-0188

[11] Lim, U., Gayles, T., Katki, H.A., Stolzenberg-Solomon, R., Weinstein, S.J., Pietinen, P., Taylor, P.R., Virtamo, J. and Albanes, D. (2007) Serum High-Density Lipoprotein Cholesterol and Risk of Non-Hodgkin Lymphoma. Cancer Research, 67, 5569-5574. http://dx.doi.org/10.1158/0008-5472.CAN-07-0212

[12] Kim, Y., Park, S.K., Han, W., Kim, D.H., Hong, Y.C., Ha, E.H., Ahn, S.H., Noh, D.Y., Kang, D. and Yoo, K.Y. (2009) Serum High-Density Lipoprotein Cholesterol and Breast Cancer Risk by Menopausal Status, Body Mass Index, and Hormonal Receptor in Korea. Cancer Epidemiology Biomarkers and Prevention, 18, 508-515. http://dx.doi.org/10.1158/1055-9965.EPI-08-0133

[13] Cust, A.E., Kaaks, R., Friedenreich, C., Bonnet, F., Laville, M., Tjonneland, A., Olsen, A., Overvad, K., Jakobsen, M.U., Chajes, V., Clavel-Chapelon, F., Boutron-Ruault, M.C., Linseisen, J., Lukanova, A., Boeing, H., Pischon, T., Trichopoulou, A., Christina, B., Trichopoulos, D., Palli, D., Berrino, F., Panico, S., Tumino, R., Sacerdote, C., Gram, I.T., Lund, E., Quiros, J.R., Travier, N., Martinez-Garcia, C., Larranaga, N., Chirlaque, M.D., Ardanaz, E., Berglund, G., Lundin, E., Bueno-de-Mesquita, H.B., van Duijnhoven, F.J., Peeters, P.H., Bingham, S., Khaw, K.T., Allen, N., Key, T., Ferrari, P., Rinaldi, S., Slimani, N. and Riboli, E. (2007) Metabolic Syndrome, Plasma Lipid, Lipoprotein and Glucose Levels, and Endometrial Cancer Risk in the European Prospective Investigation into Cancer and Nutrition (EPIC). Endocrine-Related Cancer, 14, 755-767. http://dx.doi.org/10.1677/ERC-07-0132

[14] Andreotti, G., Chen, J., Gao, Y.T., Rashid, A., Chang, S.C., Shen, M.C., Wang, B.S., Han, T.Q., Zhang, B.H., Danforth, K.N., Althuis, M.D. and Hsing, A.W. (2008) Serum Lipid Levels and the Risk of Bilary Tract Cancers and Biliary Stones: A Population-Based Study in China. International Journal of Cancer, 122, 2322-2329. http://dx.doi.org/10.1002/ijc.23307

[15] Jafri, H., Alsheikh-Ali, A.A. and Karas, R.H. (2010) Baseline and On-Treatment High-Density Lipoprotein Cholesterol and the Risk of Cancer in Randomized Controlled Trials of Lipid-Altering Therapy. Journal of the American College of Cardiology, 55, 2846-2854. http://dx.doi.org/10.1016/j.jacc.2009.12.069

[16] Melvin, J.C., Holmberg, L., Rohrmann, S., Loda, M. and Van, H.M. (2013) Serum Lipid Profiles and Cancer Risk in the Context of Obesity: Four Meta-Analyses. Journal of Cancer Epidemiology, 2013, Article ID: 823849.

[17] Vilchez, J., Martinez-Ruiz, A., Sancho-Rodriguez, N., Martinez-Hernandez, P. and Noguera-Velasco, J. (2013) The Real Role of Prediagnostic Hdl Cholesterol and the Cancer Risk: A Concise Review. European Journal of Clinical Investigation, 44, 103-114.

[18] Inamdar, P. and Mehta, G. (2011) Correlation between Obesity and High Density Lipoprotein Cholesterol (HDL-C) in Breast Cancer Patients of Southern Rajasthan. Indian Journal of Surgical Oncology, 2, 118-121. http://dx.doi.org/10.1007/s13193-011-0070-x

[19] Kim, K.I., Oh, S.W., Ahn, S., Heo, N.J., Kim, S., Chin, H.J., Na, K.Y., Chae, D.W., Kim, C.H. and Kim, S. (2012) CRP Level and HDL Cholesterol Concentration Jointly Predict Mortality in a Korean Population. American Journal of Medicine, 125, 787-795. http://dx.doi.org/10.1016/j.amjmed.2012.02.013

[20] Kucharska-Newton, A.M., Rosamond, W.D., Schroeder, J.C., McNeill, A.M., Coresh, J. and Folsom, A.R. (2008) HDL-Cholesterol and the Incidence of Lung Cancer in the Atherosclerosis Risk in Communities (ARIC) Study. Lung Cancer, 61, 292-300. http://dx.doi.org/10.1016/j.lungcan.2008.01.015

[21] Yadav, N.K., Poudel, B., Thanpari, C. and Chandra, K.B. (2012) Assessment of Biochemical Profiles in Premenopausal and Postmenopausal Women with Breast Cancer. Asian Pacific Organization for Cancer Prevention, 13, 3385-3388. http://dx.doi.org/10.7314/APJCP.2012.13.7.3385

[22] Yang, X., So, W.Y., Ma, R.C., Kong, A.P., Lee, H.M., Yu, L.W., Chow, C.C., Ozaki, R., Ko, G.T. and Chan, J.C. 
(2011) Low HDL Cholesterol, Metformin Use, and Cancer Risk in Type 2 Diabetes: The Hong Kong Diabetes Registry. Diabetes Care, 34, 375-380. http://dx.doi.org/10.2337/dc10-1509

[23] Grunnet, M. and Sorensen, J.B. (2012) Carcinoembryonic Antigen (CEA) as Tumor Marker in Lung Cancer. Lung Cancer, 76, 138-143. http://dx.doi.org/10.1016/j.lungcan.2011.11.012

[24] Molina, R., Filella, X., Auge, J.M., Fuentes, R., Bover, I., Rifa, J., Moreno, V., Canals, E., Vinolas, N., Marquez, A., Barreiro, E., Borras, J. and Viladiu, P. (2003) Tumor Markers (CEA, CA 125, CYFRA 21-1, SCC and NSE) in Patients with Non-Small Cell Lung Cancer as an Aid in Histological Diagnosis and Prognosis: Comparison with the Main Clinical and Pathological Prognostic Factors. Tumor Biology, 24, 209-218. http://dx.doi.org/10.1159/000074432

[25] Molina, R., Auge, J.M., Farrus, B., Zanon, G., Pahisa, J., Munoz, M., Torne, A., Filella, X., Escudero, J.M., Fernandez, P. and Velasco, M. (2010) Prospective Evaluation of Carcinoembryonic Antigen (CEA) and Carbohydrate Antigen 15.3 (CA 15.3) in Patients with Primary Locoregional Breast Cancer. Clinical Chemistry, 56, 1148-1157. http://dx.doi.org/10.1373/clinchem.2009.135566

[26] Molina, R., Filella, X., Lejarcegui, J.A., Pahisa, J., Torne, A., Rovirosa, A., Mellado, B., Ordi, J., Puig-Tintore, L.M., Alicarte, J., Biete, A. and Iglesias, J. (2003) Prospective Evaluation of Squamous Cell Carcinoma and Carcinoembryonic Antigen as Prognostic Factors in Patients with Cervical Cancer. Tumor Biology, 24, 156-164. http://dx.doi.org/10.1159/000073846

[27] Chevinsky, A.H. (1991) CEA in Tumors of Other than Colorectal Origin. Seminars in Surgical Oncology, 7, $162-166$. http://dx.doi.org/10.1002/ssu.2980070309

[28] Reiner, Z., Catapano, A.L., De, B.G., Graham, I., Taskinen, M.R., Wiklund, O., Agewall, S., Alegria, E., Chapman, M.J., Durrington, P., Erdine, S., Halcox, J., Hobbs, R.H., Kjekshus, J.K., Perrone, F.P., Riccardi, G., Storey, R.F. and David, W. (2011) ESC/EAS Guidelines for the Management of Dyslipidaemias. Revista Española de Cardiología, 64, 1168.e1-1168.e60. http://dx.doi.org/10.1016/j.recesp.2011.09.014

[29] Molina, R. (2003) Filella X: Marcadores tumorales: Estado actual y perspectivas de futuro II Jano. Roche Diagnostics.

[30] Mainous III, A.G., Wells, B.J., Koopman, R.J., Everett, C.J. and Gill, J.M. (2005) Iron, Lipids, and Risk of Cancer in the Framingham Offspring Cohort. American Journal of Epidemiology, 161, 1115-1122. http://dx.doi.org/10.1093/aje/kwi131

[31] Furberg, A.S., Jasienska, G., Bjurstam, N., Torjesen, P.A., Emaus, A., Lipson, S.F. and Ellison, P.T. (2005) Thune I: Metabolic and Hormonal Profiles-HDL Cholesterol as a Plausible Biomarker of Breast Cancer Risk. The Norwegian EBBA Study. Cancer Epidemiology, Biomarkers \& Prevention, 14, 33-40.

[32] Moorman, P.G., Hulka, B.S., Hiatt, R.A., Krieger, N., Newman, B., Vogelman, J.H. and Orentreich, N. (1998) Association between High-Density Lipoprotein Cholesterol and Breast Cancer Varies by Menopausal Status. Cancer Epidemiology, Biomarkers \& Prevention, 7, 483-488.

[33] LeRoith, D., Novosyadlyy, R., Gallagher, E.J., Lann, D., Vijayakumar, A. and Yakar, S. (2008) Obesity and Type 2 Diabetes Are Associated with an Increased Risk of Developing Cancer and a Worse Prognosis; Epidemiological and Mechanistic Evidence. Experimental and Clinical Endocrinology \& Diabetes, 116, S4-S6. http://dx.doi.org/10.1055/s-2008-1081488

[34] Su, F., Kozak, K.R., Imaizumi, S., Gao, F., Amneus, M.W., Grijalva, V., Ng, C., Wagner, A., Hough, G., Farias-Eisner, G., Anantharamaiah, G.M., Van Lenten, B.J., Navab, M., Fogelman, A.M., Reddy, S.T. and Farias-Eisner, R. (2010) Apolipoprotein A-I (apoA-I) and apoA-I Mimetic Peptides Inhibit Tumor Development in a Mouse Model of Ovarian Cancer. Proceedings of the National Academy of Sciences of the United States of America, 107, 19997-20002. http://dx.doi.org/10.1073/pnas.1009010107

[35] Llaverias, G., Escolà-Gil, J.C., Lerma, E., Julve, J., Pons, C. and Blanco-Vaca, F. (2012) Phytosterols Inhibit the Tumor Growth and Lipoprotein Oxidizability Induced by a 3 High-Fat Diet in Mice with Inherited Breast Cancer. Journal of Nutritional Biochemistry, 24, 39-48.

[36] Gao, F., Chattopadhyay, A., Navab, M., Grijalva, V., Su, F., Fogelman, A.M., Reddy, S.T. and Farias-Eisner, R. (2012) Apolipoprotein A-I Mimetic Peptides Inhibit Expression and Activity of Hypoxia-Inducible Factor-1Alpha in Human Ovarian Cancer Cell Lines and a Mouse Ovarian Cancer Model. Journal of Pharmacology and Experimental Therapeutics, 342, 255-262. http://dx.doi.org/10.1124/jpet.112.191544 